\title{
PENERAPAN SISTEM INFORMASI GEOGRAFIS LOKASI PEMBAYARAN LISTRIK, AIR DAN TELEPON BERBASIS ANDROID
}

\author{
Wanda Ilham ${ }^{1)}$, Dhonny Koeswoyo Setiawan ${ }^{2)}$ \\ ${ }^{1}$ Teknik Informatika, Universitas Catur Insan Cendekia, Jln Kesambi No. 202 \\ email: wandailham@cic.ac.id \\ ${ }^{2}$ Teknik Informatika, Universitas Putra Indonesia "YPTK”, Jln Lubuk Begalung \\ email: Dhonnyks32@gmail.com
}

\begin{abstract}
Abstrak
Seiring dengan pengembangan teknologi dimasa sekarang, penggunaan teknologi informasi dapat dijadikan suatu media yang dapat membantu pekerjaan manusia. Seperti halnya teknologi informasi dibidang Android yang dapat digunakan oleh siapa saja dengan mudah. GIS adalah sebuah aplikasi program yang berupa peta digital digunakan untuk membantu manusia. Peta GIS lokasi pembayaran listrik, air dan telepon berfungsi sebagai petunjuk untuk masyarakat, pemberi informasi kepada masyarakat atau pendatang seputar informasi lokasi pembayaran tersebut yang ada di kota jambi. Dalam proses perancangannya, peta dibuat menggunakan aplikasi MapInfo sedangkan aplikasi berbasis android dirancang menggunakan Eclipse. Oleh karna itu penulis mencoba merancang sebuah aplikasi android yang membantu masyarakat atau pendatang dalam mencari informasi seputar lokasi pembayaran listrik, air dan telepon di kota jambi secara cepat, praktis dan efisien.
\end{abstract}

Kata Kunci : GIS, MapInfo, Eclipse \& Android

\section{Abstract}

Along with the development of technology in the present, the use of information technology can be used as a medium that can help human work. Like information technology in the field of Android that can be used by anyone easily. GIS is an application program in the form of digital maps used to help humans. GIS map of the location of payment of electricity, water and telephone serves as a guide for the community, providing information to the public or migrants about the information on the payment location in the city of Jambi. In the design process, maps are created using the MapInfo application while android-based applications are designed using Eclipse. Therefore, the author tries to design an Android application that helps the public or migrants in finding information about the location of electricity, water and telephone payments in the city of Jambi quickly, practically and efficiently.

Keywords: GIS, MapInfo, Eclipse \& Android

\section{PENDAHULUAN}

Sebuah informasi merupakan hal yang penting dikalangan masyarakat. Banyaknya informasi yang terkadang menyulitkan seseorang untuk mencapai tempat tujuannya dan kecewa dengan hasil yang berbeda seperti yang di dengar melalui berita maupun dari mulut ke mulut. Namun hal ini sering kali tidak dapat membantu secara maksimal karena kebanyakan yang bukan warga lokal akan kebingungan harus menempuh wisata yang

JURSIMA

Jurnal Sistem Informasi dan Manajemen mana yang akan di tempuh terlebih dahulu agar sistematis dan waktu menjadi lebih efektif dan efisien. Sistem Informasi Geografis sistem yang dapat membantu menyelesaikan masalah tersebut dan memudahkan orang untuk menggali informasi tempat-tempat yang akan di kunjungi dan letaknya.

Dari hasil penelitian Gigih Prastio Indramono (2013), bahwa Sistim Informasi Geografis untuk deteksi daerah rawan longsor di Kelurahan Karang Anyar, Semarang, dapat membantu masyarakat https://ejournal.stmikgici.ac.id/ STMIK GICI 
sekirat dalam untuk mengetahui daerah yang termasuk dalam titik rawan longsor dan juga membantu pemerintah dalam pembangunan lokasi sarana dan prasarana serta memicu kesadaran masyarakat dalam hal pemanfaatan tata guna lahan. Indra Jati Kusuma (2013), Sistim informasi

Geografis Parawisa Pulau Lombok berbasis Android, dapat membantu wisatawan lokal maupun asing dalam menentukan lokasi, sarana dan prasarana yang terdapat di daerah tersebut. Kota Jambi merupakan salah satu daerah yang banyak pendatangnya,Terutama untuk para pendatang di kota jambi yang masih tidak tahu tempat pembayaran umum tersebut dan sehingga dengan adanya SIG (Sistem Informasi Geografis) berbasis android ini masyarakat dapat terbantu dan menghemat waktu dalam mendapatkan informasi dan lokasi pembayaran listrik , air dan telepon dengan mudah.

Penulis membuat aplikasi sistem informasi geografis pencarian lokasi pembayaran umum di kota jambi berbasis android berharap dapat membantu masalah yang dialami masyarakat kota jambi yang kesulitan menemukan titik lokasi pembayaran umum tersebut yang ada di kota jambi, mencari lokasi terdekat, dan membandingkan jalur terdekat untuk menuju titik lokasi tersebut yang diinginkan masyarakat Oleh karena itu melalui perancangan dan pembuatan SIG lokasi pembayaran listrik, air dan telepon diharapkan dapat menampilkan gambaran lokasi peta yang ada di Kota Jambi sehingga lebih menarik dan dapat dinikmati oleh masyarakat luas. Penyajian informasi dalam bentuk android akan memudahkan masyarakat untuk mengaksesnya.

\section{METODE PENELITIAN}

Dalam penulisan penelitian ini,penulis menggunakan beberapa metode yang sering digunakan dalam penyusunan laporan penelitian ini yang dapat dikategorikan sebagai berikut :

a. Penelitian Lapangan (Field Research)

Dalam metode ini penulis langsung turun kelapangan untuk mengumpulkan data-data yang mendukung dalam membangun skripsi ini. Dengan melakukan survey data lapangan yang berupa titik kordinat dan foto dari objek yang akan diambil untuk sebagai data.

b. Penelitian Perpustakaan (Library Research)

Melakukan pembelajaran pustaka dengan menggunakan sumbersumber bacaan seperti buku, internet dan lainnya yang berhubungan dengan masalah dalam penelitian ini.

c. Penelitian Laboraturium

Laboratority Research)

Pembuatan aplikasi yang berbasis Android yang sesuai dengan pembahasan yang dilakukan.

\section{Pengertian Sistem Informasi Geografis (SIG)}

Menurut Eddy Prahasta (2014), era komputerisasi membuka wawasan baru dalam proses pengambilan keputusan

berikut penyebaran informasi. Sehubungan dengan hal ini, data yang mewakili dunia nyata bisa disimpan dan diproses hingga disajikan dalam bentuk sederhana.

Sejak pertengahan 1970-an, dikembangkan sistem untuk menangani informasi yang bereferensi geografis. Lingkup sistem ini mencakup :

$\underline{\text { https://ejournal.stmikgici.ac.id/ }}$ STMIK GICI 
1. Pengorganisasian data dan informasi.

2. Menempatkan informasi pada lokasi geografis tertenu.

3. Melakukan komputasi, menyatakan relasi antara objek spasialdenganobjek-objek spasial lainnya, melakukan analisa spasial.

\section{Sub-Sistim SIG}

Menurut Eddy Prahasta (2014), SIG (Sistem Informasi Geografis) dapat diuraikan menjadi beberapa sub-sistem sebagai berikut :

1. Data Input :mengumpulkan, mempersiapkan, dan menyimpan data spasial dan atributnya. Sub-sistem ini bertanggung jawab dalam mengonversikan format data aslinya kedalam format SIG (Sistem Informasi Geografis).

2. Data Output : menampilkan dan menghasilkan keluaran basisdata spasialsoftcopy dan hardcopy seperti halnya tabel, grafik, report, peta, dan lain sebagainya.

3. Data Management : mengorganisasi data spasial dan tabel atribut ke dalam sistem basisdata hingga mudah untuk dipanggil kembali, di-update, - dan diedit.

4. Data Manipulation dan Analysis: menentukan informasi yang dihasilkan SIG (Sistem Informasi Geografis)

\section{Komponen SIG}

Menurut Eddy Prahasta (2014), SIG (Sistem Informasi Geografis) merupakan sistem kompleks yang umumnya terintegrasi dengan sistem komputer lainnya di tingkat fungsional dan jaringan.Jika diuraikan SIG (Sistem Informasi Geografis) terdiri dari

komponen dengan berbagai karakteristiknya :

1. Perangkat Keras, SIG (Sistem Informasi Geografis) tersedia di berbagai platform perangkat keras mulai dari kelas PC desktop, workstations, hingga multi-user host. Adapun perangkat keras yang sering digunakan untuk aplikasi SIG (Sistem Informasi Geografis) adalah (PC/CPU), mouse, keyboard, monitor (plus

VGA-cardgrafik) yang beresolusi tinggi, digitizer, printer, plotter, receiver GPS, dan scanner.

2. Perangkat Lunak, SIG (Sistem Informasi Geografis) merupakan sistem perangkat lunak dimana sistem basisdatanya memegang peran kunci. Pada SIG (Sistem Informasi Geografis) lama, sub-sistem diimpelemtasikan oleh modul perangkat lunak hinggal tidak mengherankan jikan perangkat SIG (Sistem Informasi Geografis) yang terdiri dari ratusan modul program (*.exe) yang dapat dieksekusi tersendiri.

3. Data \& informasi geografis, SIG (Sistem Informasi Geografis) dapat mengumpulkan dan menyimpan data/informasi yang diperlukan baik tidak langsung maupun langsung dengan mendijitasi data spasialnya dari peta analog dan memasukkan data atributnya dari tabel/laporan dengan menggunakan keyboard.

4. Manajemen,proyek SIG (Sistem Informasi Geografis) akan berhasil jika dikelola dengan baik dan dikerjakan oleh orang yang memiliki keahlian yang tepat pada semua tingkatan

\section{Model Data Spasial SIG}

Menurut Eddy Prahasta (2014), pada dasarnya secara konseptual terdapat dua model data spasial, rester dan vector. Seiring perkembangan, impelentasi data spasial sudah berkembang jauh.Pada mulanya, setiap SIG memiliki data spasial format sendiri.Tetapi dengan pupolaritas format tertentu, maka setiap SIG pun menyediakan Fungsionalitas export and import dari format data spasial standart tersebut.

https://ejournal.stmikgici.ac.id/ 
5. Kesalahan pada penampilan peta.

\section{Analisa Sistem}

Dalam tahapan analisa masalah ini penulis melakukan analisa pada sistem informasi geografis, dimana nantinya sistem ini dapat digunakan oleh masyarakat yang ingin mencari lokasi objek pembayaran listrik, air dan telepon di kota jambi. Selain itu sistem juga harus dibuat semudah mungkin karna sistem ini akan digunakan oleh masyarakat umum. Penganalisaan masalah ini adalah proses yang penting dalam sebuah sistem, karena pada perancangan sistem yang baru perlu diperhatikan pada sistem yang sedang berjalan. Penganalisaan sistem ini bertujuan untuk memperbaharui sistem yang telah ada dengan cara melengkapi sistem tersebut, oleh karena itu sistem harus dibuat seteliti mungkin sehingga dapat mengatasi masalah yang ada.

\section{Pemecahan Masalah}

Dari penguraian masalah yang ada di Kota Jambi, khususnya masalah didalam mencari objek lokasi pembayaran listrik, air dan telepon di kota jambi maka penulis membantu untuk memudahkan permasalahan yang ada dengan cara membuat Sistem Informasi Geografis penyebaran objek lokasi pembayaran listrik, air dan telepon dilengkapi dengan koordinat lokasi tersebut, oleh karena itu penulis merancang sebuah aplikasi berbasis android yang berisikan tentang lokasi dari objek pembayaran listrik, air dan telepon, dimana pengguna aplikasi tersebut dapat mengetahui lokasi tersebut dengan cepat.

\section{Indentifikasi Variable Sistem \\ Berikut adalah data-data yang diperlukan dalam membangun Sistem}


Informasi Geografis dapat dilihat pada Tabel 4.1 berikut ini.

\section{Tabel 1 Tabel Nama Alamat Objek Lokasi Di Kota Jambi}

\begin{tabular}{|c|c|c|c|c|c|c|c|}
\hline \multicolumn{4}{|c|}{ Lokası Di Kota Jambı } & & 11 & & \\
\hline \multirow[t]{2}{*}{1} & \multirow{2}{*}{$\begin{array}{l}\text { Jl. Lkr Timur } \\
\text { I }\end{array}$} & \multirow[t]{2}{*}{-1.626048} & \multirow[t]{2}{*}{103.649180} & 30 & Kebun Handil & -1.620273 & 103.618166 \\
\hline & & & & 31 & Jl. Sumatera & -1.624029 & 103.611747 \\
\hline 2 & Jl. Lkr Sel. II & -1.649406 & 103.645418 & 32 & $\overline{D . L}$ & -1.623793 & 103.621342 \\
\hline 3 & Lrg.mustika & -1.641919 & 103.641567 & & Penjaitan & & \\
\hline 4 & $\begin{array}{l}\text { Perumahan } \\
\text { liverpool }\end{array}$ & -1.641017 & 103.639858 & $\begin{array}{r}35 \\
z S L\end{array}$ & $\begin{array}{l}\text { J1. R. Wijaya } \\
U L A N\end{array}$ & -1.637748 & 103.624524 \\
\hline
\end{tabular}

\begin{tabular}{|l|lr|l|l|}
\hline 5 & $\begin{array}{l}\text { Jl. } \\
\text { Muis }\end{array}$ & Abdul & -1.642766 & 103.636607 \\
\hline
\end{tabular}

\begin{tabular}{|l|l|l|l|}
\hline 6 & $\begin{array}{l}\text { Jl. Marsda } \\
\text { Abdurahman }\end{array}$ & -1.634678 & 103.635719 \\
\hline
\end{tabular}

\begin{tabular}{l|l|l|l}
\hline 7 & Lrg. Langkat & -1.630562 & 103.634781 \\
\hline 8 & Sorkano & -1.62705 & 103.63534
\end{tabular}

\begin{tabular}{|l|l|l|l|}
\hline 8 & Jl. Soerkarno & -1.627405 & 103.635434 \\
\hline
\end{tabular}

\begin{tabular}{|l|lr|l|l|}
\hline 9 & $\begin{array}{l}\text { Jl. } \\
\text { Siagian }\end{array}$ & R.B. & -1.623368 & 103.642267 \\
\hline
\end{tabular}

\begin{tabular}{|l|l|l|l|}
\hline 10 & $\begin{array}{l}\text { Lrg. Fatahilah } \\
\text { I }\end{array}$ & -1.616475 & 103.652472 \\
\hline 11 & $\begin{array}{l}\text { Jl. Sentot } \\
\text { Alibasha }\end{array}$ & -1.606275 & 103.646809 \\
\hline
\end{tabular}

\begin{tabular}{l|lll|l}
\hline 12 & Jl. H. & Adam & -1.627605 & 103.631359 \\
\hline
\end{tabular}

\begin{tabular}{|l|lr|l|l}
\hline \multicolumn{1}{l|}{ Malik } & & \\
\hline 13 & $\begin{array}{l}\text { Jl. KH } \\
\text { Ibrahim }\end{array}$ & -1.621816 & 103.630628 \\
\hline
\end{tabular}

\begin{tabular}{|l|l|l|l|}
\hline 14 & $\begin{array}{l}\text { Barua } \\
\text { II }\end{array}$ & -1.614139 & 103.630504 \\
\hline 15 & $\begin{array}{l}\text { Jl. Kol Pol M } \\
\text { Thaher }\end{array}$ & -1.609456 & 103.630115 \\
\hline & Jl. Org ayo & -1.598567 & 103.629950 \\
\hline
\end{tabular}

\begin{tabular}{|l|l|l|l}
\hline 16 & Jl. Orang kayo & -1.598567 & 103.629950 \\
\hline
\end{tabular}

\begin{tabular}{|l|l|l|l} 
& pingai & & \\
\hline 17 & $\begin{array}{l}\text { Jl. Panglima } \\
\text { polim }\end{array}$ & -1.594681 & 103.634792 \\
\hline
\end{tabular}

\begin{tabular}{|l|l|l|l|}
\hline 18 & Smpg. Durian & -1.591455 & 103.629832 \\
\hline 19 & $\begin{array}{l}\text { Jl. Kom. Pol } \\
\text { Ahmat Bastari }\end{array}$ & -1.592064 & 103.628393 \\
\hline
\end{tabular}

\begin{tabular}{|l|l|l|l|}
\hline & Ahmat Bastari & & \\
\hline 20 & $\begin{array}{l}\text { Jl. Kol Moh. } \\
\text { Insyah }\end{array}$ & -1.591818 & 103.623695 \\
\hline
\end{tabular}

\begin{tabular}{l|lr|l|l} 
& Jl. & Jend. & -1.615877 & 103.627292
\end{tabular}

\begin{tabular}{|c|c|c|c|}
\hline & Sudirman 2 & & \\
\hline$\overline{22}$ & $\begin{array}{l}\text { Jl. Jend. } \\
\text { Sudirman } 2\end{array}$ & -1.611551 & 103.624725 \\
\hline$\overline{23}$ & $\begin{array}{lr}\text { Jl. } & \text { Jend. } \\
\text { Sudirman no. } \\
16\end{array}$ & -1.610337 & 103.623999 \\
\hline$\overline{24}$ & $\begin{array}{l}\text { Smpg. } \\
\text { Jelutung }\end{array}$ & -1.602532 & 103.618671 \\
\hline 25 & $\begin{array}{l}\text { Jl. Hayam } \\
\text { Wuruk }\end{array}$ & -1.604156 & 103.617115 \\
\hline 26 & Jl. Cempaka & -1.605966 & 103.614324 \\
\hline 27 & $\begin{array}{lr}\text { Jl. } & \text { Hayam } \\
\text { Wuruk } & \text { No. }\end{array}$ & -1.609551 & 103.615252 \\
\hline
\end{tabular}

JURSIMA

Jurnal Sistem Informasi dan Manajemen

\begin{tabular}{|l|l|l|l|}
\hline & 129 & & \\
\hline 28 & $\begin{array}{l}\text { Jl. Gajah } \\
\text { Mada }\end{array}$ & -1.615563 & 103.615426 \\
\hline 29 & $\begin{array}{l}\text { Jl. Gajah } \\
\text { Mada } \\
\text { II }\end{array}$ & -1.614037 & 103.612096 \\
\hline 30 & Kebun Handil & -1.620273 & 103.618166 \\
\hline 31 & Jl. Sumatera & -1.624029 & 103.611747 \\
\hline 32 & $\begin{array}{l}\text { Jl. D.L } \\
\text { Penjaitan }\end{array}$ & -1.623793 & 103.621342 \\
\hline $\begin{array}{l}\text { 35 } \\
\text { JIM. R. Wijaya }\end{array}$ & -1.637748 & 103.624524 \\
\hline
\end{tabular}

\section{KESIMPULAN}

Berdasarkan analisa yang telah dilakukan pada bab sebelumnya Sistem Informasi Geografis Objek lokasi pembayaran listrik, air dan telepon di kota jambi maka dapat diambil kesimpulan sebagai berikut:

1. Dengan merancang penyebaran objek lokasi pembayaran listrik, air dan telepon di kota jambi pada Sistem Informasi Geografis (SIG) berbasis android dapat menentukan lokasi pembayaran listrik, air dan telepon di kota jambi.

2. Sistem Informasi Geografis (SIG) penyebaran objek lokasi pembayaran listrik, air dan telepon di kota jambi ini dibangun untuk memberikan informasi kepada masyarakat atau pendatang seputar objek lokasi pembayaran listrik, air dan telepon yang ada kota jambi.

3. Sistem Informasi Geografis (SIG) ini dapat menampilkan informasi melalui smartphone android dari setiap lokasi pembayaran listrik, air dan telepon di kota jambi yang dapat membantu masyarakat atau pendatang dalammenemukan lokasi pembayaran listrik, air dan telepon di kota jambi. 


\section{UCAPAN TERIMA KASIH}

Terima kasih untuk Tuhan yang maha Esa dan Keluarga sudah support dan juga STMIK Gici telah memberikan ruang untuk kami melakukan penelitian, dan terima kasih untuk editor pak dasril aldo sudah mau mereview jurnal kami

\section{DAFTAR PUSTAKA}

Adi Nugroho. 2009. "Rekayasa PerangkatLunak Menggunakan UML dan Java". Yogyakarta: CV Andi Offset.

Andry Kurniawan. 2012."Rekayasa Perangkat Lunak Aplikasi Penjualan Pada Toko StoryTime Factory Outlet Menggunakan Pemograman Java". Tugas Akhir. Padang: Fakultas Teknologi Informasi Universitas Andalas.

Dony Novaliendry.2011. "Multimedia Pembelajaran Bahasa Mandarin dan website Promosi". Tugas Akhir. Padang: Fakultas Teknik Universitas Negri Padang.

Eddy Prahasta. 2014. "Sistim Informasi Geografis: Konsep- Konsep Dasar (Prefektif Geodesi \& Geomatika)". Bandung: Informatika Bandung.

Edgar Winata, Johan Setiawan. 2013."Analisis dan Perancangan Prototipe Aplikasi Tracking Bus Universitas Multimedia Nusantara Pada Platform Android" .TugasAkhir.Tanggerang:ProdiSisti m Informasi Universitas Multimedia Nusantara.

Gigih Prastyo Indramoro. 2013. "GIS untuk Deteksi Rawan Longsor Studi Kasus di Kelurahan Karang Anyar Gunung Semarang”.TugasAkhir. Semarang: Fakultas Ilmu Komputer
Universitas Dian Nuswantoro Semarang.

Murya Yoesef. 2014. "Pemograman Android Blackbox". Bandung: Jasakom.

Rizki Putra, Bambang Darmono Yuwono. 2015. "Pembuatan

Aplikasi Mobile GIS Berbasis Android Untuk Informasi Parawisatadi Kabupaten Gunungkidul”. Tugas Akhir. Semarang: Fakultas Teknik Universitas Diponegoro.

Rosa A.S, M. Shalahuddin. 2014."Rekayasa Perangkat Lunak Terstruktur dan Berorientasi Objek". Bandung: Informatika Bandung.

Siti Fatimah Nurdiah P, Ani Aprianni. 2014. "Aplikasi Edukasi "Ceria" Berbasis Android Sebagai Media Pembelajaran Anak". Tugas Akhir. Semarang: Fakultas Komputer STMIK MD. https://ejournal.stmikgici.ac.id/ STMIK GICI 